\title{
VANILLIC DIETHYLAMIDE (ETHAMIVAN) AND THE HYPOVENTILATION SYNDROME IN THORACIC SURGERY
}

\author{
Jean-Paul Dechêne, m d a
}

The hypoventilation syndrone with carbon dioxide ietention, collection of secretions, and consequent atelectasis is one of the most important postoperative and postanaesthetic complications encountered in thoracic surgery, especially that of the lungs Hence the necessity for the anaesthetist to maintain ventulation not only during the operation proper but also postoperatively To this end, several means, mechanical as well as chemical, are made avallable by modern therapy, apart from sound prophylaxis Such prophylactıc treatment consists of the use of an adequate but non-depressant premedication and light anaesthesia which will allow both optimum oxygenation and ventilation The ventilation may then be measured with a Wright respirometer as the patient is aroused, and if necessary, a Bird intermittent positive pressure apparatus is used for as long as the minute ventilation is not back to near its normal level, that is in the neighbourhood of 6 to 8 litres for an adult, with $400-500 \mathrm{c} \mathrm{c}$ of tidal anr and breathing rate of 16-20 per minute As normal respiration is restored, the patient is again left to himself but is given oxygen with a NCG or a BLB mask If ventilation is considered satisfactory by the anaesthetist, the patient is then taken to the intensive care unit, where the same procedure will be repeated if necessary and as often as needed

Controlled ventilation is administered through a tracheotomy cannula and with an adequate respurator-the Burd or Bennett apparatus in our hospital-for extreme cases of hypoventilation, which is caused, usually, by a major cardiorespiratory insufficiency already present before the operation, particularly in the patient with a pulmonary condition

\section{Vanillic Diethylamide (EThamivan)}

\section{Chemustry}

Ethamivan is a white, crystalline, odouless powder comparatively insoluble in water It melts at $955^{\circ}$ and its molecular weight is 22326 Ethamivan is supplied as a 5 per cent diethanolamme aqueous solution for mtravenous use and in tablet form for oral use

\section{Pharmacology}

Respuratory stimulation mediated principally via the medullary centre is the most important pharmacological effect of Ethamivan Large doses will eventually arouse the chemoreceptors and stop in the medulla the mhibiting impulses coming from higher nervous centres

\footnotetext{
Department of Anaesthesia \& Resuscitation, Laval Hospital, Quebec
} 
The drug also exerts an arousing effect through direct stimulation of the cortex On the average, the respiratory effects of Ethamivan are seen within 30 seconds following an intravenous injection and last for about 10 minutes Tidal air is increased by 48 per cent and the respiratory rate by 24 per cent

The depth of breathing is therefore the feature which is most particularly involved The action of the drug may be maintamed with continuous intravenous infusion and by carefully adjusting the drip rate The effects of the oral form are less pronounced, they are seen between one and four hours after intake depending on individual patient responsiveness

No serious untoward effects on the blood pressure and cardiovascular system have ever been reported in man when the drug is used in therapeutic doses Moreover, no tachyphylactic effect has been observed, which means that consecutive doses of intravenous Ethamivan are as effective as the first dose However, some secondary effects have been reported such as sneezing, coughing, pruntus, agitation, but they can usually be avoided We shall give a detailed account of these effects when describing the procedure employed

\section{Our Techinioue}

This analeptic respuratory medication has been employed by numerous investigators for various causes of central nervous system and respiratory depression This explains, in our opinion, the variety of techniques resorted to Ethamivan is being used to treat intoxication of the central neivous system by depressing agents, to promote awakening or lighten general anaesthesia especially for the ambulatory patient, and to prevent or treat the hypoventilation syndrome in the presence of respiratory insufficiency with $\mathrm{CO}_{2}$ retention, which is seen most often in pulmonary surgery and with the postoperative and postanaesthetic sequelae This syndrome is marked by drowsiness, headache, lethargy, weariness, mental aberration, a period of irascibility and restlessness, tremor of the extremities, tachypnoea with sharply reduced depth of respiration, cardiac decompensation, cyanosis, even apnoea and coma

In this clinical study we are concerned with the latter indication exclusively Consequently, a continuous 01 per cent intravenous infusion appeared to us to be quite in order since we are dealing with a long-term treatment Yet, some more serious cases of respiratory insufficiency did requie a single injection of $\mathbb{E}$ thamivan before the contmuous drup infusion to combat a severe hypoventilation syndrome faster and more effectively In such cases, a single dose of $100 \mathrm{mg}$ Ethamivan in $20 \mathrm{cc}$ of saline is given This dilution allows a slow injection of the drug with the chief advantage of avoiding the side-effects altogether

Finally, the oral route is also used after the intravenous infusion to secure a prolonged effect of the adjuvant analeptic medication when the patient can be fed normally, that is 48 hours after the operation on the average This oral medication is only used when the pulmonary condition of the patient (asthma, chronic bronchitis, emphysema) calls for a prolonged course of treatment of the hypoventilation syndrome, which always remains a possibility in the presence of 
such a pathologic condition For a week or even longer, the patient receives 60 mg tablets, four tumes a day The 01 per cent continuous infusion technique was the only one used and required, immediately after the operation, to offset the hypoventilation syndrome in 85 per cent of the cases reported here The cases discussed here were all postoperative patients lacking adlequate ventilation It must also be pointed out that the halothane-ether anaesthetic technique used with our patients permits a prompt and immediate postoperative arousal and that in no circumstance did we have to resort to Ethamivan to spur awakening or reduce anaesthesia

It appeared that the most effective dose of Ethamivan was between 005 and $007 \mathrm{mg}$ per $\mathrm{kg}$ per minute to provide satisfactory ventilation while averting the side-effects from the drug

\section{Results}

We have studied the effects of Ethamivan in the treatment of the hypoventilation syndrome in 101 cases of thoracic surgery, particularly surgery of the lungs

\section{General Revew of the Cases Studued}

The patients included in the study are a group of 101 consecutive cases of thoracic surgery treated in our institution from April 1962 to December 1963 These were pulmonary cases for the most part, all of them being affected by the hypoventilation syndrome in various degree This syndrome was either detected preoperatively in patients whose cardiorespiratory function was notably inadequate, or diagnosed postoperatively through clinical signs of hypoventilation (rapid breathing and drastically reduced depth of respiration), spurometry with deficieni minute ventilation (tidal air less than half its normal level), and studies of the arterial blood which indicated respiratory acidosis

Patients were men and women whose ages were between 16 and 70 years Their condition (tuberculosis, diaphragmatic hernia, bronchiectasis, and cancer) justified a more or less imperative and urgent thoracic operation The following shows the type and number of surgical operations performed 35 lobectomies, 4 pleurectomies, 28 pneumonectomies, 2 partial lobectomies, 2 Shede operations, 8 thoracoplasties, 18 pulmonary biopsies and thoracotomies, 2 diaphragmatic hernias, 1 oesophageal resection, 1 sternochondroplasty

\section{Discussion}

Most of the cases in the study presented respiratory insufficiency diagnosed preoperatively from a study of their pulmonary function This is generally true for most surgical procedures performed in cases of established tuberculosis The eight thoracoplasties and the two Shede operations were necessitated for treatment of bronchopleural fistulae or stubborn cases of empyema associated with pneumonectomies ( 16 out of 28 tuberculosis cases) where the function is of course drastically reduced

This is equally true in the treatment of cancer, where owing to neoplastic 
involvement the pulmonary function is carried more and more by only one lung In this series resection was possible in 12 cases of 28 with neoplasm

The cases of lobectomy (tuberculosis, cancer, and bronchiectasis) were all classified beforehand as having various degrees of respiratory insufficiency because of a serious pulmonary condition such as asthma, chronic bronchitis, and emphysema

The two cases of diaphragmatic hernia were patients with marked obesity In such patients postoperative hypoventilation is a common occurrence

The woman with sternochondroplasty was also stricken with bronchiectasis involving the pulmonary function

The case of cancerous cardia was a 70 year-old man Restrictions in gaseous exchange are always more critical in older than in younger adults

Finally, the four pleurectomies were all performed on young people Good postoperative ventilation might normally be expected in these, but postoperative recovery proved to be extremely disappointung, from this point of view, because of pains associated with a new spontaneous pneumothorax

Among the patients reported above, there were a few cases of lobectomy and of partial lobectomy where pulmonary function was not deficient preoperatively Howeve1, this respinatory insufficiency was observed postoperatively for various reasons, such as lack of physiotherapy, marked obesity, restlessness, overdepressing sedation, and it was treated accordingly

In review, the hypoventilation syndrome was present at different times and in varying degrees in all the cases studied and reported in this paper The condition was relieved by the administration of intiavenous vanillic acid diethylamide by continuous infusion

\section{Specific Advantages}

The use of respiratory analeptics has often given rise to heated argument in the field of postanaesthetic resuscitation We as e convinced that $\mathbb{E}$ thamivan given by continuous infusion to cases of hypoventilation syndrome has been highly beneficial to our patients It improved therr postoperative ventilation and avoided in them a postoperative tracheotomy, which is always a risky surgical procedure that should be abstanned from if at all possible Nevertheless, this drug used alone does not provide an over-all means for treating all cases of respiratory depression efficiently At no tume should it be substituted for the basic prophylactic and therapeutic measures afforded by sound anaesthesia and resuscitation on the other hand, we think that it may be defintely valuable when properly used in conjunction with other therapeutic measures for respiratory depression such as manual or mechanical intermittent positive pressure

We feel that other observers have been right in calling vanillic acid diethylamide a chemical respirator and the least that can be said about it is that it represents a new method of combating the hypoventilation syndrome more effectively This method proved to be very efficient as we used it with our patients, and the incidence of pulmonary involvement due to hypoventilation was reduced to a minimum In fact, only a few catheter aspirations of the trachea were required, and no tracheotomies were found necessary postoperatively The routine 
use of this intravenous "chemical respirator" was undoubtedly instrumental in making the postoperative intensive care of our patients more simple

In summary, there is certanly a place for the use of continuous intravenous infusion of vanillic diethylamide (Ethamivan) in the inodern treatment of the hypoventilation syndrome in thoracic surgery, and if this technique is applicable in pulmonary surgery it perhaps merits a more genera clinical trial in general, surgery, where occasionally pulmonary pathology malkes the hypoventilation syndrome a problem in the postoperative period Ethamivan is therefore another tool put at the disposal of the clinician by modern therapeutics for the ventilation of his patient

\section{RÉSUMÉ}

L'emploı d'analeptıques respuatorres a souvent été l'objet de sérieuses controverses en anesthésie réanımation Pour notre part, dans plusieurs cas atteints du syndrome d'hypoventilation, nous avons jugé que l'emplor "d'Ethamivan," en perfusion intra-veineuse contmue, a rendu de grands services à nos malades et leur a permis de mieux se ventiler post-opératorrement, tout en évitant à l'occasion une trachéotomie post-opératorre qui demeure toujours une chirurgie délicate à éviter si possible Nous restons cependant convancu que cette médication seule n'est pas une thérapeutique universelle pour traiter efficacement toutes les dépressions respiratoires rencontrées en médecine Elle ne dolt en aucune façon nous farre oublier les mesures prophylactiques et thérapeutiques de base d'une bonne anesthésıe-réanımation Mais par allleurs, nous croyons qu'elle peut définitıvement rendre service, si elle est associée à bon escient aux autres thérapeutiques de la dépression respiratorre par exemple à la P P I manuelle ou mécanique

A notre opınıon, le diéthyl-amide vamillique a été surnommé avec raison par les auteurs le respirateur chimique de la ventilation et le moins qu'on puisse dire à son sujet c'est qu'il représente une méthode nouvelle de lutter plus efficacemeni contre le syndrome d'hypoventilation Entre nos mains du moins, la méthode s'est avérée très efficace et l'incidence des complications pulmonarres propres aे l'hypoventiation a été réduite au minimum chez nos malades En effet seulemen quelques aspirations trachéales au cathéter ont été rendues nécessaures et aucuné trachéotomie a dû être pratiquée dans les suites opératoures de ces dermiers C'esi donc dire que l'emploi continu de ce "respirateur chimique" par voie intra veineuse a certanement contribué à simplifier les soins intensifs de nos malades à. la période postopératorre

En résumé dans le traitement moderne du syndrome d'hypoventilation en chirurgie thoracique, il y a certamement place pour l'usage par voie intra-vemeuse d'une perfusion contınue de diéthyl-amide vanillique commercialısé sous le nom "d'Ethamıvan" Et si cette technique est applicable avec succès en chirurgie pulmonaı e, elle mérite peut-être un essaı clinıque plus généralısé en chırurgie générale où à l'occasion une pathologie pulmonaure fat crandre à la pénode post-opératorre la présence de ce syndrome d'hypoventilation Avec "Ethamivan" c'est donc une arme de plus que la thérapeutique moderne met à la disposition du clinicien pour la bonne ventilation de som malade. 


\section{REFERENCES}

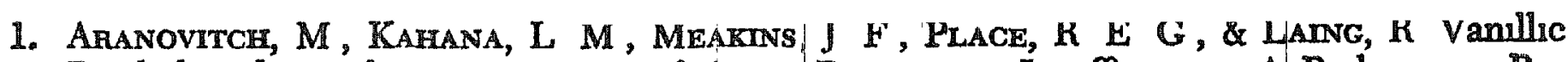
Diethylamide in the Management of Acute Respuratory Insufficiency A Prelmanary Report Canad M A J 85875 (1961)

2 Cotrifent, $R$ F \& Stomltivg, V Pulmonary Function Test in the Immediate Postoperative Penod Med Times (Apnl 1961)

3 MILLR, M J, HAND, B M, \& CRELLIN, J A Pharmacologic Effects of Intravenous Vanullic Acid Diethylamide in Man Clin Pharmacol \& Therap 2689 (1961)

4 Mmien, W F, ARChdeR, $R \mathbb{K}$, TAyLoR, H F, \& Ossenfort, W F Severe Respuratory Depression J A M A 180805 (1962)

5 Romagnou, A \& Diamond, M J Some Trials with Vanillic Diethylamide A New Analeptic Canad Anaesth Soc J 8551 (1961)

6 Silipo, S, Hagenorn, C, Rosenstein, I N, \& Baum, G L Expenences with Ethamivan, a New Respuratory Stmulant and Analeptid Agent J A A (1961)

7 Slater, H M The Use of Vanillic Acid Diethylamide following 41 (1962)

Anesth \& Analg 